\title{
Corrosion inhibition of iron in chloride media by the aqueous extract of Curcuma longa rhizome powder
}

\author{
Imen AbidlI ${ }^{1,}$, Nébil Souissi ${ }^{1}$, X. Ramón Novoa ${ }^{2}$ \\ ${ }^{1}$ University of Tunis El Manar, Preparatory Institute for Engineering Studies, El \\ Manar, Tunis, Tunisia \\ ${ }^{2}$ University of Vigo, School of Industrial Engineering, Vigo, Galicia, Spain \\ ${ }^{*}$ Corresponding author: imen.abdili@fst.utm.tn
}

\begin{abstract}
The effect of the aqueous extract of Curcuma Longa Rhizome Powder and their main constituents involve phenolic compounds, as an iron corrosion inhibitor in $0.1 \mathrm{M} \mathrm{NaCl}$ solution was tested. Electrochemical impedance spectroscopy (EIS) was employed as the main experimental technique to assess the electrochemical behavior of iron in different concentrations of Curcuma extract. EIS revealed an increase of the charge transfer resistance with increasing inhibitor concentration. The temperature and immersion time effects on the corrosion behavior of iron without and with the extract of Curcuma were also studied. The inhibition action of the extract was discussed in view of the Langmuir adsorption isotherm.
\end{abstract}

Keywords: Adsorption isotherm; barrier properties; EIS; iron; surface analysis.

\section{Introduction}

Corrosion results from a chemical to electrochemical action of a service environment on metals and alloys. The consequences are significant in various fields and particularly in the industry: reduction of production, replacement of corroded parts, accidents involving risk of pollution are frequent events. The associated economic impact is relevant and cannot be ignored. Corrosion is the phenomenon in which metals tend, under the action of atmospheric agents or chemical reagents, to return to their original state of oxides, sulphides, carbonates, which involves the deterioration of their properties. It is therefore a process of degradation of metals that, except for metals such as gold and platinum, always tend to deteriorate in contact with the atmosphere, water, and various corrosive environments
(Etteyeb \& Nóvoa, 2016). However, different methods as cathodic protection, the use of coatings or inhibitors are available to slow down the deterioration process.

Recent regulations that ban the use of potentially toxic inhibitors as chromate, nitrite, etc. complicate the application of effective anti-corrosion treatments and therefore justify the research for new means of protection, working in a wide range of service environments, including acidic (Ma et al., 2000), alkaline (Joiret et $a l .$, 2002), and saline solutions.

It is very important to choose compounds safe for handling and environmentally friendly to use as corrosion inhibitors. The replacement of synthetic inhibitors, toxic for the environment and humans, requires finding molecules in Nature to perform as efficient 
corrosion inhibitors. Today there is a strong research activity on environmentally-friendly corrosion inhibitors. Recent research has focused on corrosion inhibitors that are non-toxic, benign, inexpensive, renewable, and readily available in different parts of plant extracts (E.E. Oguzie, 2008; Okafor et al., 2008; Okafor, Ebenso \& Ekpe, 2010).

The new European directives concerning the development of sustainable industrial processes are being more and more severe in terms of ecology. Thus, the development of eco-compatible and biodegradable corrosion inhibitors is becoming nowadays a very important issue. It is particularly for this reason and their remarkable inhibitory properties that the use of organic inhibitors has been widely acclaimed during the last decade (FAUSTIN, 2013).

Various natural substances have been tested as corrosion inhibitors for steel in neutral media (Talebian et al., 2018; Tian et al., 2018). Among these, plant extracts (Abdel-Gaber et al., 2006; Lebrini et al., 2011), fruit peel extracts (Da Rocha, da Cunha Ponciano Gomes, and D'Elia, 2010; Behpour et al., 2012), leaf extracts (Deng $\& \mathrm{Li}, 2012$ ), or even coffee ground (Torres et al., 2011), or honey (El-Etre \& Abdallah, 2000) have shown their efficiency. The corrosion inhibition ability of plant extracts is generally attributed to the presence of secondary metabolites containing antioxidant polyphenolic compounds like alkaloids, flavonoids, or condensed tannins (Rahim et al., 2007; Lebrini et al., 2011).

This work is dedicated to the study of the inhibition of iron corrosion in a chloridecontaining neutral electrolyte by the aqueous extract of Curcuma. Electrochemical techniques were employed for the characterization and synthesis of oxide layers on the surface of iron samples. Those layers were also characterized from the physicochemical point of view, identifying the different phases involved.
All those results are presented and discussed.

\section{Experimental}

The cylindrical samples iron sample 99.99 $\% \mathrm{Fe}$ (Good fellow) were cast in epoxy resin, and the cross-section $\left(\mathrm{S}=0.2 \mathrm{~cm}^{2}\right)$ was exposed to the electrolyte. The surface was manually abraded using $\mathrm{SiC}$ paper grit size (grade 500-1000-1200) and rinsed in distilled water.

Rhizome (Curcuma longa) powder $(25 \mathrm{~g})$ was weighed and boiled for $3 \mathrm{~h}$ with $200 \mathrm{~mL}$ distilled water. After, distilled water was added up to $1 \mathrm{~L}$, and gentle stirring was carried out for 11 hours. Finally, centrifugation was carried out to separate the suspended solids.

The solutions employed were arranged using analytical grade chemicals and deionized water $(\rho \geq 18 \mathrm{M} \Omega \mathrm{cm})$. The concentration range studied was $10-50 \mathrm{mg}$ $\mathrm{L}^{-1}$. The temperature range studied was $30-$ $50{ }^{\circ} \mathrm{C}$. The $\mathrm{pH}$ of the solution at $22 \pm 2{ }^{\circ} \mathrm{C}$ was 7.21.

An Autolab® potentiostat PGSTAT 20 equipped with FRA32 module was used for the electrochemical characterization using Electrochemical Impedance Spectroscopy (EIS). The electrochemical cell was a typical three-electrode cell assembly bearing the iron electrode surface as a working electrode, a saturated calomel electrode (SCE) as the reference electrode, and a large area graphite sheet was the counter electrode (CE). The data analysis was conducted using the dedicated Autolab® software that implements the fitting impedance utility based on the B. A. Boukamp algorithm (Boukamp, 1986). The impedance measurements were performed at the open circuit potential (EOCP); the frequency range was from $100 \mathrm{kHz}$ down to $0.01 \mathrm{~Hz}$. A $10 \mathrm{mV}$ rms amplitude sinusoidal wave perturbation was imposed on the corroding system with 10 frequency values per decade. The sample surface was examined for its structural and 
topographical features using a JEOL JSM65105 Scanning electron microscope (SEM).

The pure aqueous extract and the scratched corrosion products formed on the iron surface were analyzed separately with the help of FT-IR spectra (NICOLETFTIR spectrometer Model 6700) using the $\mathrm{KBr}$ pellet method.

\section{Results and discussion}

EIS was applied to check out the Curcuma extract's inhibition efficiency on the iron corrosion in a $0.1 \mathrm{M} \mathrm{NaCl}$ electrolyte.

\subsection{Open circuit potential measurements}

The open-circuit potential (EOCP) of the iron samples was monitored for $7 \mathrm{~h}$ from immersion. (Figure 1) depicts the evolution of the (EOCP) vs. time obtained for the three solution conditions tested. In the blank solution, the open-circuit potential shifts negatively from $-0.54 \mathrm{~V}$ to a relatively stable value of $-0.64 \mathrm{~V}$. In the presence of $50 \mathrm{mg} \mathrm{L}^{-1}$ of Curcuma extract, the potential corrosion shifts also negatively, but reaching values more negative than those of the blank solution.

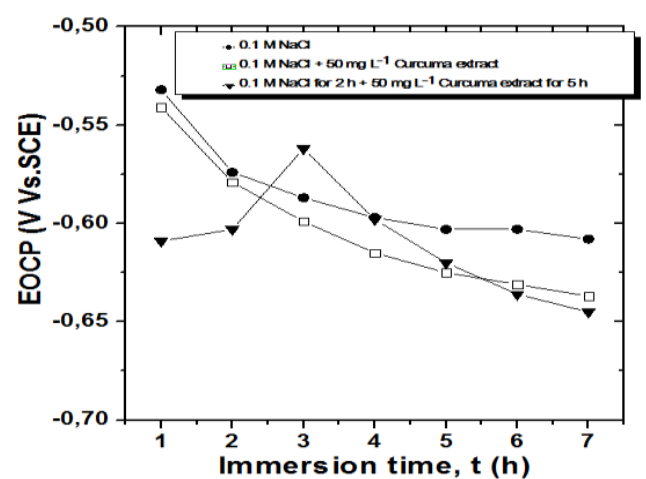

Fig. 1. Evolution of the open circuit potential with immersion time for iron sample in the three conditions tested :(•) 0.1 $\mathrm{M} \mathrm{NaCl}$ solution (blank), ( $\square) 0.1 \mathrm{M} \mathrm{NaCl}$ solution $+50 \mathrm{mg} \mathrm{L}^{-1}$ of Curcuma extract, and $(\boldsymbol{\nabla})$ blank solution with $50 \mathrm{mg} \mathrm{L}^{-1}$ of Curcuma extract added after $2 \mathrm{~h}$ of immersion.
The addition of Curcuma extract after $2 \mathrm{~h}$ of immersion makes the corrosion potential to shift anodically for the first hour, followed by a decay reaching the lowest potential recorded at the end of the immersion periods.

The observed variations in the initial EOCP values can be attributed to differences in the initial surface oxidation states. The general trend of potential decreasing is relevant in this context because it can be a consequence of the corrosion process itself, leading to a diminution of the local concentration of oxygen (Ateya, El-Anadouli, \& ElNizamy, 1984). Also relevant is the anodic potential shift observed after the addition of $50 \mathrm{mg} \mathrm{L}^{-1}$ of Curcuma extract, which points to a process of adsorption of molecules that will change (at least temporarily) the corrosion mechanism to an anodic control (Sherif, Erasmus, \& Comins, 2010; Deus et al., 2012).

\subsection{EIS results}

Electrochemical impedance spectroscopy is a technique conventionally used to study the mechanisms involved in corrosion processes (Fattah-alhosseini et al., 2009). The surface properties, electrode kinetics, and mechanistic information can be obtained from the impedance spectra (Lorenz \& Mansfeld, 1981) by using either a kinetic model or a suitable electrical equivalent circuit, which is the choice here.

\subsubsection{Effect of the concentration}

The corrosion behavior of iron in $0.1 \mathrm{M}$ $\mathrm{NaCl}$ solution in the absence and presence of Curcuma extract was investigated by the EIS method at room temperature after immersion for $15 \mathrm{~min}$. (Figure 2(a)) shows the corresponding Nyquist-plots obtained at the open circuit potential (Cole \& Cole, 1941). Two highly depressed capacitive arcs can be differentiated in the high and 
low-frequency regions. The low-frequency capacitive arc shows the typical shape for a bounded diffusion phenomenon, more evident in the solution involving $50 \mathrm{mg} \mathrm{L}^{-1}$ of Curcuma extract. The insert in (Figure 2) shows for the highest Curcuma concentration, a small capacitive arc at the high-frequency limit that could be related to the dielectric behavior of the adsorbed film of Curcuma, in agreement with the EOCP data discussed in section 3.1. Although relevant to confirm the adsorption of inhibitor, this small capacitive contribution cannot be differentiated for lower concentrations of inhibitor and will not be considered explicitly to model the impedance data.
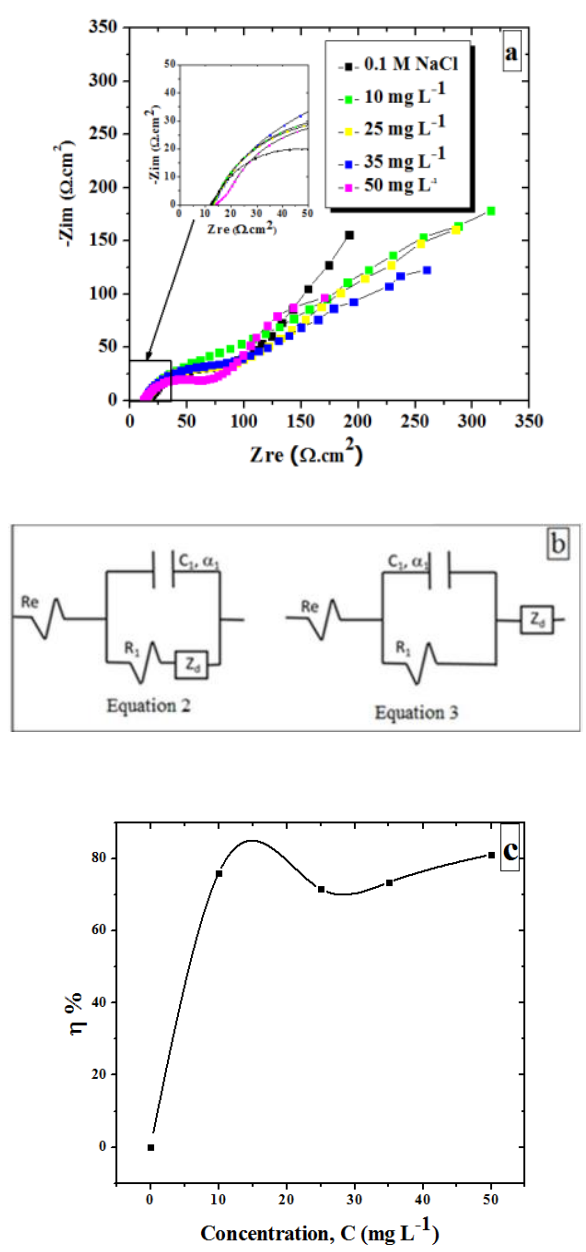

Fig. 2. Inhibition of different Curcuma concentrations on the iron surface in $0.1 \mathrm{M}$ $\mathrm{NaCl}$ at $22{ }^{\circ} \mathrm{C}$. a) Nyquist Impedance spectra. b) Equivalent circuits employed to model the impedance data. c) Inhibition efficiency in percentage $\eta(\%)$ as a function of Curcuma extract concentration.

However, it allows us to identify the inhibition mechanism, which blocks the surface by adsorption of the inhibitor. The ionic resistance afforded by such adsorbed layer is small and thus, the associated RC time constant lies out of the frequency window scanned. Only for $50 \mathrm{mg} \mathrm{L}^{-1}$ concentration, the $\mathrm{R}$ value is high enough to increase the time constant up to values in the frequency scanned, as shown in the inset of (Figure 2(a)). This kind of mechanism has already been proposed in the literature (Johnsirani et al., 2013), although also involving $\mathrm{Zn}^{2+}$ species.

The low-frequency arc corresponds to the diffusion of the cathodic reactant that can be modeled with equation (1) corresponding to bounded diffusion. $\mathrm{R}_{\mathrm{d}}$ holds for the diffusion resistance and $\tau \mathrm{d}$ to the time constant associated with the diffusion process. $\mathrm{j}=(-1)^{1 / 2}$ and $\omega=2 \pi \mathrm{f}$.

$Z_{d}(\omega)=R_{d} \tanh \left(j \omega \tau_{d}\right) / \sqrt{j \omega \tau_{d}}$

The high-frequency part of the impedance spectrum (down to about $10 \mathrm{~Hz}$ ) can be fitted in the general case with only one time constant so that the impedance spectra have been modeled using equation (2).

$$
\begin{aligned}
& Z(\omega)=R_{e}+ \\
& R_{1} /\left(j \omega R_{1} C_{1}\right)^{\alpha_{1}}+\left(1 / 1+\left(Z_{d}(\omega) / R_{1}\right)\right)
\end{aligned}
$$

In equation (2), $R_{e}$ corresponds to the electrolyte resistance, $R_{1}$ to the charge transfer resistance, $\mathrm{C}_{1}$ to the double-layer capacitance, and $\alpha_{1}$ account for a Cole-Cole type dispersion factor, which is equivalent to a CPE behavior distributed normally to the electrode surface (Orazem et al., 2013). In some cases, mainly dealing with the highest concentration of inhibitor tested, the better fitting quality was obtained, 
placing the diffusion element in series to the interfacial capacitance, as shown in equation (3).

Nevertheless, this aspect does not affect the discussion here, which is based on the kinetic parameter $R_{1}$ and will not be developed further.

$Z(\omega)=R_{e}+{ }^{R_{1}} / 1+\left(j \omega R_{1} C_{1}\right)^{\alpha_{1}}+$

$Z_{d}(\omega)$

The equivalent circuits corresponding to equation (2) and equation (3) are shown in (Figure 2(b)).

Using a SIMPLEX method (Guitián, Nóvoa, \& Puga, 2011) that considers the charge transfer kinetics of the inhibited and uninhibited processes (inversely proportional to the $R_{1}$ parameter), the $R_{1}$ measurements were employed to determine the inhibition efficiency, $\eta \%$, according to equation (4).

$$
\begin{aligned}
& \eta(\%)= \\
& \left.\left(R_{1(\text { inh })}-R_{1(\text { blank })}\right) / R_{1(\text { inh })}\right) 100
\end{aligned}
$$

Where $\mathrm{R}_{1 \text { (blank) }}$ and $\mathrm{R}_{1 \text { (inh) }}$ correspond to the charge transfer resistances obtained without and with Curcuma extract, respectively.
The corrosion kinetic parameters summarized in (Table 1) show that the charge transfer resistance $\mathrm{R}_{1}$ and diffusion resistances lie in the same order of magnitude, indicating a mixed-type control of the corrosion mechanism.

Moreover, the time constant of the diffusion process results in about $1 \mathrm{~Hz}$, consistent with the oxygen diffusion process in quiescent solutions that involves a diffusion layer in the order of $30 \mu \mathrm{m}$. The $\mathrm{C}_{1}$ values are quite high for what is expected for a double-layer capacitance, especially for the blank solution.

Two main factors contribute to those high values. The high active surface due to the iron corrosion products, of conducting character, and the contribution of the redox processes linked to magnetite transformations in the oxide film (Joiret $e t$ al., 2002).

Moreover, $\mathrm{C}_{1}$ decreases with the inhibitor concentration, which points to adsorption of Curcuma extract molecules at the metal/solution interface, i.e., partial coverage of the active surface by species of

Table 1. Impedance parameters for the corrosion of iron in $0.1 \mathrm{M} \mathrm{NaCl}$ solution containing different concentrations of Curcuma extract.

\begin{tabular}{|cccccc|}
\hline \hline $\mathbf{C}\left(\mathbf{m g ~ \mathbf { ~ L } ^ { - 1 } )}\right.$ & $\mathbf{R}_{\mathbf{1}}\left(\boldsymbol{\Omega} \mathbf{~ c m}^{\mathbf{2}}\right)$ & $\mathbf{C}_{\mathbf{1}}\left(\boldsymbol{\mu} \mathbf{F} \mathbf{~ c m}^{-\mathbf{2}}\right)$ & $\mathbf{R}_{\mathbf{d}}\left(\mathbf{\Omega} \mathbf{~ c m}^{\mathbf{2}}\right)$ & $\tau_{\mathbf{d}}(\mathbf{s})$ & $\mathbf{\eta} \mathbf{\%}$ \\
\hline- & 30.1 & 1460 & 33.6 & 1.4 & \\
10 & 83.7 & 386 & 12.1 & 0.037 & 64.0 \\
25 & 79.1 & 324 & 100 & 1.7 & 61.9 \\
35 & 96.1 & 875 & 37.6 & 0.16 & 68.7 \\
50 & 116 & 346 & 127 & 2.1 & 74.1 \\
\hline
\end{tabular}


Table 2. Data obtained from EIS spectra for iron $0.1 \mathrm{M} \mathrm{NaCl}$ without and with $50 \mathrm{mg} \mathrm{L}^{-1}$ of Curcuma extract at different temperatures.

\begin{tabular}{|c|c|c|c|c|c|c|}
\hline $\mathrm{C}\left(\mathrm{mg} \mathrm{L}^{-1}\right)$ & $\mathbf{T}\left({ }^{\circ} \mathbf{C}\right)$ & $R_{1}\left(\Omega \mathrm{cm}^{2}\right)$ & $\mathrm{C}_{1}\left(\mu \mathrm{F} \mathrm{cm} \mathbf{~}^{2}\right)$ & $R_{d}\left(\Omega \mathrm{cm}^{2}\right)$ & $\tau \mathrm{d}(\mathrm{s})$ & $\boldsymbol{\theta}$ \\
\hline \multirow[t]{5}{*}{0} & 25 & 30.1 & 1460 & 33.6 & 1.4 & - \\
\hline & 35 & 22.8 & 220 & 136 & 2.1 & - \\
\hline & 40 & 20.3 & 363 & 78 & 1.2 & - \\
\hline & 45 & 21.2 & 866 & 48 & 2.7 & - \\
\hline & 50 & 18.6 & 983 & 23.7 & 1.7 & - \\
\hline \multirow[t]{5}{*}{50} & 25 & 116 & 346 & 127 & 2.1 & 74.1 \\
\hline & 35 & 47.3 & 327 & 188 & 1.8 & 51.8 \\
\hline & 40 & 43.2 & 2420 & 60.9 & 1.2 & 53.0 \\
\hline & 45 & 46.6 & 9500 & 257 & 14.6 & 54.5 \\
\hline & 50 & 41.1 & 2810 & 419 & 60.7 & 54.7 \\
\hline
\end{tabular}

dielectric character (Guitián, Nóvoa, \& Puga, 2011).

The kinetic parameter, $\mathrm{R}_{1}$, increases with the concentration of the inhibitor. The greatest effect was observed in the absence of Curcuma extract that gives the $\mathrm{R}_{1}$ value of $30.1 \Omega \mathrm{cm}^{2}$ and $\mathrm{C}_{1}$ value of $1460 \mu \mathrm{F}$ $\mathrm{cm}^{-2}$, whereas when $50 \mathrm{mg} \mathrm{L}^{-1}$ is added, $\mathrm{R}_{1}$ is increased to $116 \Omega \mathrm{cm}^{2}$ and the $C_{1}$ value is reduced to $346 \mu \mathrm{F} \mathrm{cm}^{-2}$. The changes in both parameters, $\mathrm{R}_{1}$ and $\mathrm{C}_{1}$, are of similar magnitude, about $75 \%$, which, again, points to a geometrical factor effect: the partial coverage of the interface by the inhibitor, without changes in the corrosion mechanism.

(Figure 2(c)) presents $\eta(\%)$ obtained according to equation (4), at $22 \pm 2{ }^{\circ} \mathrm{C}$. Exploration of the spectra shows an initially fast increase in $\eta(\%)$ with the addition of $10 \mathrm{mg} \mathrm{L}^{-1}$ of Curcuma extract followed by marginal increase with further additions of the inhibitor. This illustrates that Curcuma extract acts as an efficient inhibitor even at low concentrations. These data obviously display that Curcuma extract inhibits corrosion of iron in $0.1 \mathrm{M} \mathrm{NaCl}$ solution at all the concentrations used in this study, and $\eta(\%)$ reach a maximum value of $74.1 \%$.
3.2.2. Effect of the temperature

To determine the effect of this factor on the inhibitory power of the organic compounds studied, we carried out a study between 25 ${ }^{\circ} \mathrm{C}$ and $50{ }^{\circ} \mathrm{C}$, in the absence and in the presence of $50 \mathrm{mg} \mathrm{L}^{-1}$ of Curcuma extract.

The experiments were carried out with the maximum concentration of the extract of Curcuma because the best inhibition efficacy was obtained for this concentration. The best-fitting parameter results obtained from the EIS measurements are summarized in (Table 2). The data in (Table 2) show that the diffusion time constant remains steady for the blank solution, at around $1 \mathrm{~s}$; however, it increases up to $60 \mathrm{~s}$ for the higher temperatures of the inhibited solution, which means a slowdown of the diffusion process, probably because of the formation of a gel-like layer in the vicinity of the electrode. This view is compatible with the observed increase in $\mathrm{R}_{\mathrm{d}}$ and $\mathrm{C}_{1}$.

Moreover, as expected, the charge transfer resistance, $R_{1}$, decreases by raising the temperature. In the blank solution, $\mathrm{R}_{1}$ decreases from 30.1 to $18.6 \Omega \mathrm{cm}^{2}$ (38\%) and from 116 to $41.1 \Omega \mathrm{cm}^{2}(64 \%)$ in the presence of the inhibitor. i.e., in the presence of the inhibitor, the corrosion rate has a stronger temperature dependence. 


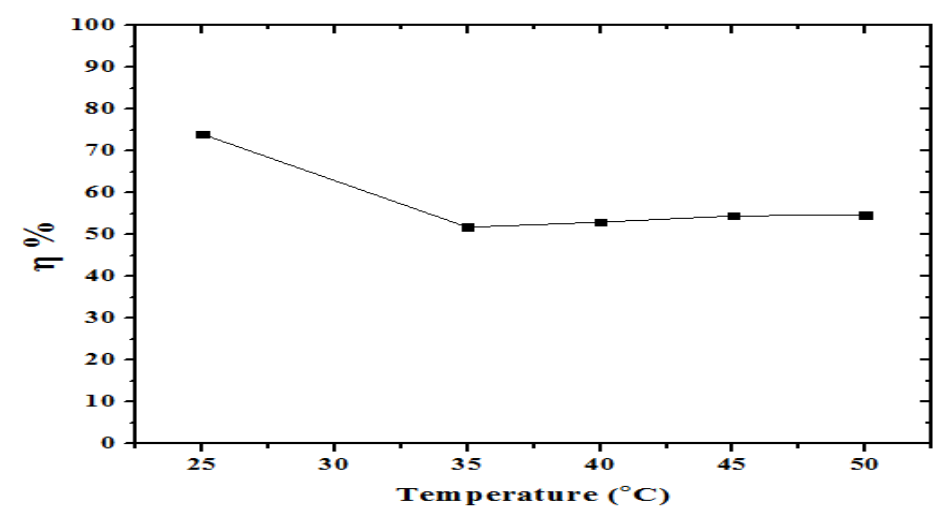

Fig. 3. Effect of temperature on Curcuma extract inhibition efficiency for iron corrosion in $0.1 \mathrm{M} \mathrm{NaCl}$

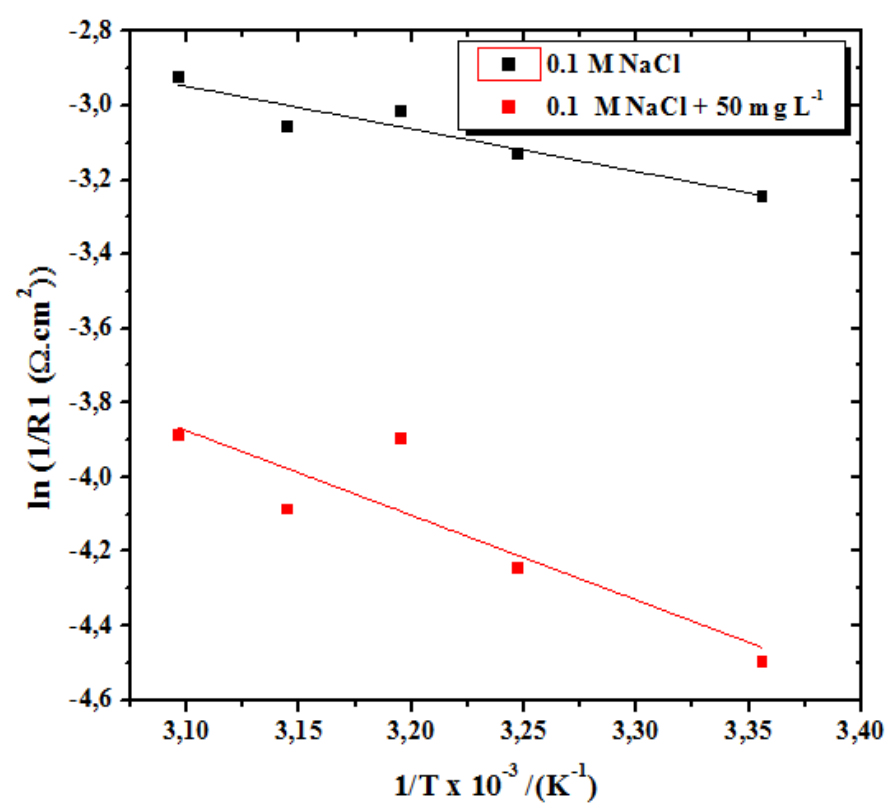

Fig. 4. Arrhenius plots for iron in $0.1 \mathrm{M} \mathrm{NaCl}$ without and with $50 \mathrm{mg} \mathrm{L}^{-1}$ of Curcuma extract.

The inhibition efficiency decreased with increasing temperature from 74.1 to $54.7 \%$, corresponding to 25 and $50{ }^{\circ} \mathrm{C}$, respectively. This variation in $\eta(\%)$ as a function of temperature is depicted in (Figure 3). The corresponding Arrhenius plots in the absence and presence of Curcuma extract are shown in (Figure 4).

The corrosion rate being inversely proportional to the charge transfer resistance, $\mathrm{R}_{1}$, allows obtaining the activation energy, Ea, via the Arrhenius equation (Equation 5), where $\mathrm{k}$ is the

$$
\ln \left(\frac{1}{R_{t}}\right)=\ln (K)-\frac{E_{a}}{R} \frac{1}{T}
$$
pre-exponential factor and $\left(-E_{a} / R\right)$ the slope of the regression lines in (Figure 4). 
Table 3. Data obtained from EIS spectra for iron in $0.1 \mathrm{M} \mathrm{NaCl}$ without and with $50 \mathrm{mg} . \mathrm{L}^{-1}$ at 25 and $50{ }^{\circ} \mathrm{C}(1-7 \mathrm{~h})$ using an equivalent circuit in Figure 3(b).

\begin{tabular}{|c|c|c|c|c|c|c|}
\hline Media/inhibitor & Time (h) & $R_{1}\left(\Omega \mathbf{c m}^{2}\right)$ & $\mathrm{C}_{1}\left(\mu \mathrm{F} \mathrm{cm} \mathrm{cm}^{-2}\right)$ & $\mathbf{R}_{\mathrm{d}}\left(\Omega \mathrm{cm}^{2}\right)$ & $\tau_{d}(s)$ & n \% \\
\hline \multirow[t]{3}{*}{$0.1 \mathrm{M} \mathrm{NaCl}$} & 1 & 24.3 & 1780 & 2470 & 233.6 & - \\
\hline & 3 & 37.6 & 4520 & 10000 & 31140 & - \\
\hline & 7 & 28.6 & 7360 & 108 & 11.5 & - \\
\hline \multirow{3}{*}{$\begin{array}{c}0.1 \mathrm{M} \mathrm{NaCl}+50 \\
\mathrm{mg} . \mathrm{L}^{-1}\end{array}$} & 1 & 413 & 835 & 156 & 3.3 & 94.1 \\
\hline & 3 & 609 & 757 & 359 & 106.3 & 93.8 \\
\hline & 7 & 683 & 444 & 183 & 13.5 & 95.8 \\
\hline \multirow[t]{2}{*}{$0.1 \mathrm{M} \mathrm{NaCl}$} & 1 & 11.8 & 215 & 613 & 0.4 & - \\
\hline & 2 & 17.5 & 224 & 759 & 0.5 & - \\
\hline $50 \mathrm{mg} \cdot \mathrm{L}^{-1}$ added & 3 & 33.1 & 315 & 1100 & 0.4 & - \\
\hline $\begin{array}{c}\text { after } 2 \mathrm{~h} \\
\text { immersion }\end{array}$ & 7 & 53.5 & 431 & 1270 & 0.5 & 46.5 \\
\hline
\end{tabular}

The Ea values determined from the slope of the Arrhenius plots in the figure are 11.47 $\mathrm{kJ} \mathrm{mol}^{-1}$ in the absence of inhibitor and $22.79 \mathrm{~kJ} \mathrm{~mol}^{-1}$ in the presence of Curcuma extract. According to (Eduok, Umoren, \& Udoh, 2012) and to (Gomma, 1998), the corrosion process acquires the character of a diffusion-controlled reaction in which at a lower temperature, the quantity of inhibitor present at the metal surface is greater than that at a higher temperature, which engendered that higher $\mathrm{Ea}$ values in inhibited solutions reveal physical adsorption. This is in agreement with the increased $R_{d}$ and $\tau_{d}$ values obtained for the higher temperatures in the presence of inhibitor.

\subsubsection{Effect of immersion time}

The EIS method consists of measuring the electrode's response to a sinusoidal modulation of the low amplitude of the potential as a function of frequency. It does not disturb the system, and it is possible to follow it over time. Immersion time studies were performed in $0.1 \mathrm{M} \mathrm{NaCl}$ without and with $50 \mathrm{mg} \mathrm{L}^{-1}$ of Curcuma extract for $7 \mathrm{~h}$ at the respective open-circuit potentials. EIS data were registered every $1 \mathrm{~h}$ during the experiment. (Table 3) list the corresponding best-fit electrochemical parameters. It is observed that the value of charge transfers resistance $\left(R_{1}\right)$ increases slightly in blank solution from 24.3 to $28.6 \Omega \mathrm{cm}^{2}$ while the double layer capacitance $\left(\mathrm{C}_{1}\right)$ increases from 1780 to $7360 \mu \mathrm{F} \mathrm{cm}^{-2}$, which indicates that a film of iron oxide was formed (FioriBimbi et al., 2015; Qafsaoui et al., 2018) which involves redox activity (Etteyeb \& Nóvoa, 2016). The formation of this layer slows down the oxygen diffusion rate, as evidenced by the high $\tau_{\mathrm{d}}$ values.

By adding of $50 \mathrm{mg} \mathrm{L}^{-1}$ of Curcuma extract, the $R_{1}$ parameter increases greatly. After $1 \mathrm{~h}$ of immersion, Curcuma extract inhibited the iron corrosion by about $94 \%$. After $7 \mathrm{~h}$, the inhibition efficiency reached a value of $95.8 \%$. In fact, $\mathrm{R}_{1}$ increased from 413 to $683 \Omega \mathrm{cm}^{2}$, and $\mathrm{C}_{1}$ decreased from 835 to $444 \mu \mathrm{F} \mathrm{cm}^{-2}$. The moderate decrease of $\mathrm{C}_{1}$ and the rise of $\mathrm{R}_{1}$ with increasing time suggest a film thickening.

The addition of an inhibitor after $2 \mathrm{~h}$ of immersion in the blank solution makes $\mathrm{R}_{1}$ to increase from 17.5 at $2 \mathrm{~h}$ (addition) to 53.5 $\Omega \mathrm{cm}^{2}$ at $7 \mathrm{~h}$ (5h from addition), which evidences the ability of the inhibitor to 
adsorb also on a pre-rusted surface. Surprisingly, the $\mathrm{C}_{1}$ increases from 215 to $431 \mu \mathrm{F} \mathrm{cm}^{-2}$, which can be understood considering the associated decreasing observed for $\mathrm{R}_{\mathrm{d}}$. It seems that the adsorption of inhibitor involves the displacement of the outermost part of the oxides film forming a jelly-like structure. This kind of peeling-off effect will decrease the film thickness of the pre-rusted surface.

\subsection{Adsorption isotherm}

The fraction of electrode surface occupied by the inhibitor adsorbed is a function of the inhibitor concentration and can be represented by adsorption isotherms. The surface coverage values $(\theta)$ for different concentrations of Curcuma extract in $0.1 \mathrm{M}$ The surface coverage values $(\theta)$ for different concentrations of Curcuma extract in $0.1 \mathrm{M} \mathrm{NaCl}$ solution is evaluated by the inhibition efficiency values using the equation (6):

$\theta=\eta(\%) / 100$

The values of surface coverage $(\theta)$ are presented graphically according to the suitable adsorption isotherm. The $\mathrm{C}_{\mathrm{inh}} / \boldsymbol{\theta}_{\text {inh }}$ curve as a function of the concentration is linear for $50 \mathrm{mg} \mathrm{L}^{-1}$ of Curcuma extract in $0.1 \mathrm{M} \mathrm{NaCl}$ at room temperature, and it is depicted in (Figure 5).

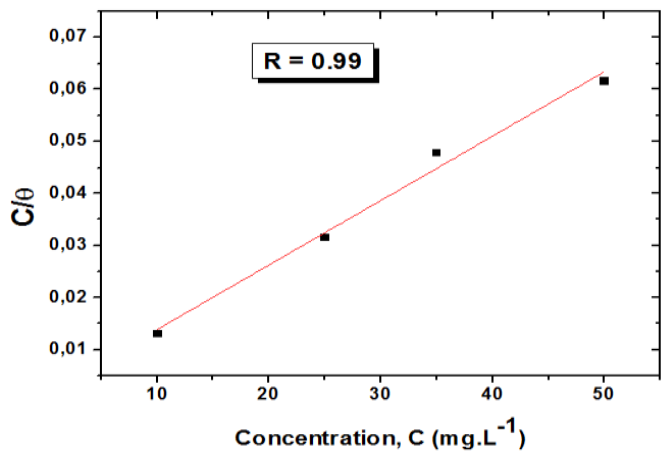

Fig. 5. Linear regression of Langmuir adsorption obtained for iron in $0.1 \mathrm{M} \mathrm{NaCl}$ in the presence of different concentrations of Curcuma extract at $22^{\circ} \mathrm{C}$.

It is observed that the adsorption of Curcuma extract on the surface iron in chloride media obeys the Langmuir adsorption isotherm, allowing to equation (7):

$C_{i n h} /_{\theta}=1 / K_{\text {ads }}+C_{i n h}$

Where $\mathrm{C}_{\mathrm{inh}}$ is the bulk inhibitor concentration, $\mathrm{k}_{\text {ads }}$ the equilibrium constant of the adsorption process, and $\theta$ is the surface coverage. Using the correlation coefficient $\left(\mathrm{R}^{2}\right)$ as the criterion to choose the proper adsorption isotherm, the strong correlation $\left(\mathrm{R}^{2}=0.99\right)$ obtained from (Figure 5) suggests that the adsorption of the inhibitor on the iron surface obeys the Langmuir adsorption isotherm (El-Hajjaji et al., 2018). The $\mathrm{k}_{\mathrm{ads}}$ was hence determined for the temperature range 298-323 K using equation (6), and regressions as in (Figure 5).

The Langmuir model assumes that there are a fixed number of sites on the surface. Each of these sites can adsorb only one particle. Moreover, since adsorbed particles' interactions are neglected, the adsorption energy is constant (Bilgiç \& Çaliskan, 1999). The surface coverage is proportional to the concentration of inhibitor $\mathrm{C}_{\text {inh }}$ and to the fraction of unoccupied adsorption sites (1- $-\theta)$ (Monk \& Mortimer, 2008). The constant adsorption $\mathrm{k}_{\mathrm{ads}}$ is associated to the standard free energy of adsorption ( $\Delta \mathrm{G}^{\circ}$ ads) according to equation (7) (El-Hajjaji et al., 2018):

$\Delta \mathrm{G}_{\text {ads }}^{\circ}=-\mathrm{RT} \operatorname{Ln}\left(55.5 \mathrm{~K}_{\mathrm{ads}}\right)$

Where 55.5 is the molar concentration of water in the solution. $\mathrm{T}$ is the absolute temperature $(\mathrm{K})$, and $\mathrm{R}$ is the gas constant $\left(8.314 \mathrm{~J} \mathrm{~K}^{-1} \mathrm{~mol}^{-1}\right)$.

The thermodynamic data obtained for 50 mg $\mathrm{L}^{-1}$ of Curcuma extract, using adsorption isotherms at different temperatures, is presented (Figure 6). The $\Delta \mathrm{G}^{\circ}$ ads negative values inform about the 
spontaneity of the adsorption process and the stability of the adsorbed layer on the metal surface.

Generally, $\Delta \mathrm{G}^{\circ}$ ads values close to $-20 \mathrm{~kJ}$ $\mathrm{mol}^{-1}$ or lower, are related to electrostatic interactions between the charged molecules and the charged metal (physical adsorption), whereas those more negative than $-40 \mathrm{~kJ} \mathrm{~mol}^{-1}$ involve sharing a charge transfer between the organic molecules and the metal surface (chemisorption) (Donahue \& Nobe, 1965; Khamis, Bellucci \& Latanision, 1991). The $\Delta \mathrm{G}^{\circ}$ ads values determined here range from -59.31 to $-64.28 \mathrm{~kJ} \mathrm{~mol}^{-1}$, showing that the extract molecules are chemisorbed to the metallic surface.

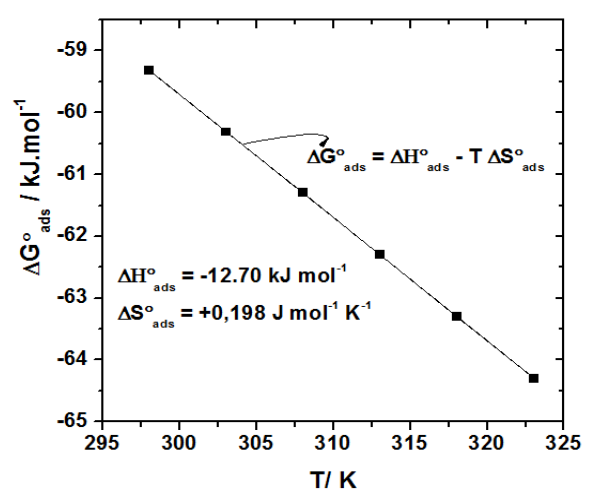

Fig. 6. The plot of the standard free energy of adsorption vs. Temperature.

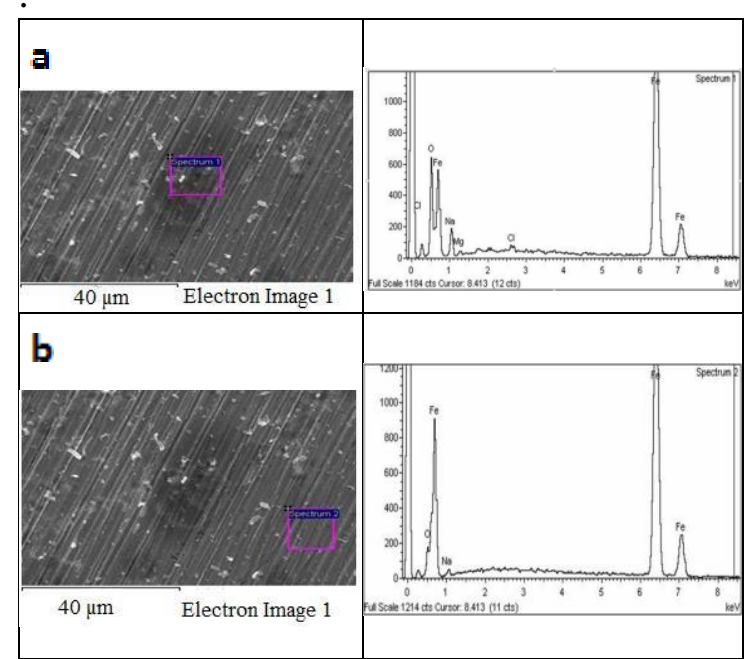

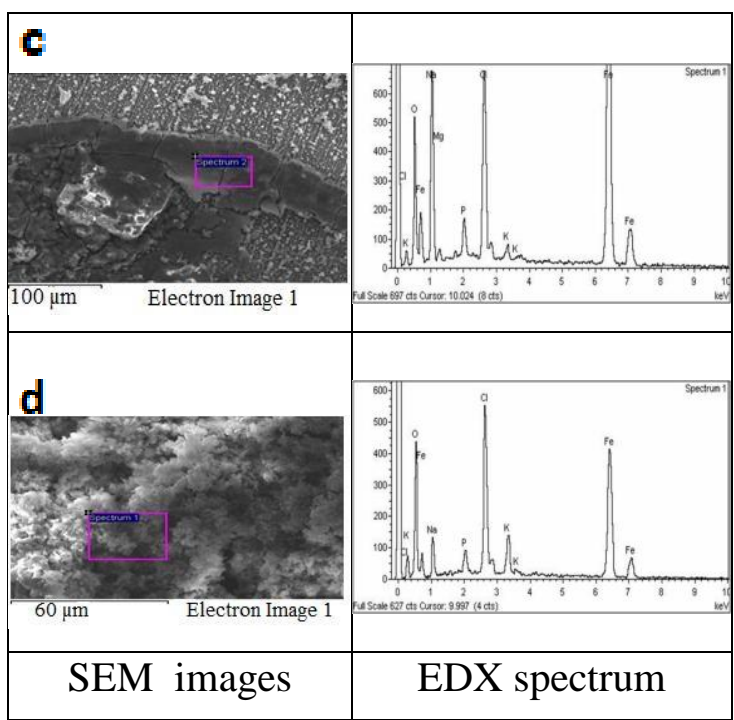

Fig. 7. SEM images and their corresponding spectra of the iron surface with different locations and chemical mapping $\mathbf{a}$ ) and $\mathbf{b}$ ) after $7 \mathrm{~h}$ immersion time in $0.1 \mathrm{M} \mathrm{NaCl}+50 \mathrm{mg} \mathrm{L}^{-1}$ of Curcuma extract at $25^{\circ} \mathrm{C}$. c) and d) after $7 \mathrm{~h}$ immersion time in $0.1 \mathrm{M} \mathrm{NaCl}+50 \mathrm{mg} \mathrm{L}^{-1}$ of Curcuma extract, at $50^{\circ} \mathrm{C}$.

(Figure 6) allows the direct obtention of $\Delta \mathrm{H}^{\circ}{ }_{\text {ads }}$ and $\Delta \mathrm{S}^{\circ}$ ads values that are $-12.7 \mathrm{~kJ}$ $\mathrm{mol}^{-1}$, and $0.2 \mathrm{~J} \mathrm{~mol}^{-1} \mathrm{~K}^{-1}$, respectively. The $\Delta \mathrm{H}^{\circ}$ ads value confirms the chemisorption nature of the adsorption process. Additionally, the small value of $\Delta \mathrm{S}^{\circ}$ ads indicates only a little increase in disorder at the interface due to adsorbed species complexes (Durnie et al., 1999).

\subsection{Surface characterization}

(Figure 7) displays SEM images and EDX analysis of iron samples after immersion for $7 \mathrm{~h}$ in $0.1 \mathrm{M} \mathrm{NaCl}$ solution with and without $50 \mathrm{mg} \mathrm{L}^{-1}$ of Curcuma extract

The surface morphology of iron immersed in $0.1 \mathrm{M} \mathrm{NaCl}$ in the presence of inhibitor illustrated in (Figure 7(a), (b)) appears to be intact. The corresponding EDX spectra indicate a higher amount of $\mathrm{Fe}$, which may be interpreted as an absence of a significant amount of corrosion products shielding the $\mathrm{Fe}$ substrate. However, a severe attack is observed in (Figure 7(c)) for iron immersed in chloride media with inhibitor after $7 \mathrm{~h}$ at $50{ }^{\circ} \mathrm{C}$. The 
degradation of the surface is intense. The corresponding EDX spectrum reveals that the degraded layer contains a large amount of $\mathrm{Fe}$, which shows that iron binds with other species to form a protective layer, as suggested by the thermodynamic data $\left(\Delta \mathrm{G}_{\text {ads }}^{\circ}\right.$ is more negative than $-50 \mathrm{~kJ} \mathrm{~mol}^{-1}$ ). The chemical mapping for the specific region depicted in (Figure 7(d)) where abundant deposits accumulate indicates an increase of the amount of $\mathrm{Cl}$, which suggests the presence of trapped $\mathrm{NaCl}$ or bound $\mathrm{Cl}$, but also $\mathrm{P}$ and $\mathrm{K}$, elements that can come only from the organic extract. The relative intensity of these two signals, particularly that corresponding to $\mathrm{P}$, indicates the accumulation of the interface's organic molecules.

\subsection{FT-IR and Raman analysis}

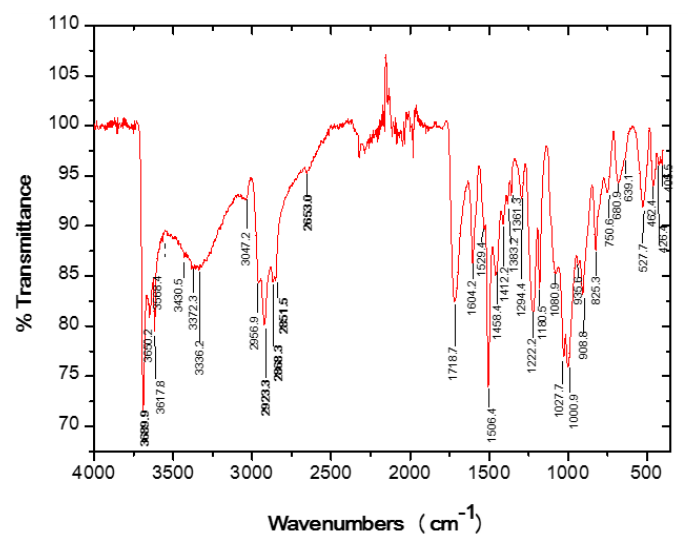

Fig. 8. The FTIR spectrum of the film of the iron surface after $7 \mathrm{~h}$ of immersion time in $0.1 \mathrm{M} \mathrm{NaCl}$ containing $50 \mathrm{mg} \mathrm{L}^{-1}$ of Curcuma extract at $25^{\circ} \mathrm{C}$.

The Curcuma dye extract was evaporated to dryness to get a solid mass. Its FTIR spectrum is interpreted in previous works (Banerjee \& Malhotra, 1992) Complex-formation ability is an important factor to show the surface adsorption of the active component of the extract on the metal surface. It is difficult to assign the inhibitive effect to a particular constituent.
The FTIR spectrum of the protective film formed on the metal surface after immersion in the solution containing $\mathrm{NaCl}$ $0.1 \mathrm{M}$ and $50 \mathrm{mg} \mathrm{L}^{-1}$ of Curcuma extract is shown in (Figure 8). It contains phenolic $\mathrm{OH}$ groups, alkyl aryl ether groups, and $\mathrm{C}=\mathrm{O}$ groups in conjugation with double bonds. The phenolic $\mathrm{O}-\mathrm{H}$ stretch shifted from $3689.9 \mathrm{~cm}^{-1}$. The $-\mathrm{CH}$ band was assigned at $2923.3 \mathrm{~cm}^{-1}$. The $\mathrm{C}=\mathrm{O}$ stretching frequency was assigned at $1718.7 \mathrm{~cm}^{-1}$. The asymmetrical $\mathrm{C}-\mathrm{O}-\mathrm{C}$ stretch of the ether group vibrated at $1222.2 \mathrm{~cm}^{-1}$. The symmetrical $\mathrm{C}-\mathrm{O}-\mathrm{C}$ stretch of the ether group corresponds to $1027.7 \mathrm{~cm}^{-1}$.

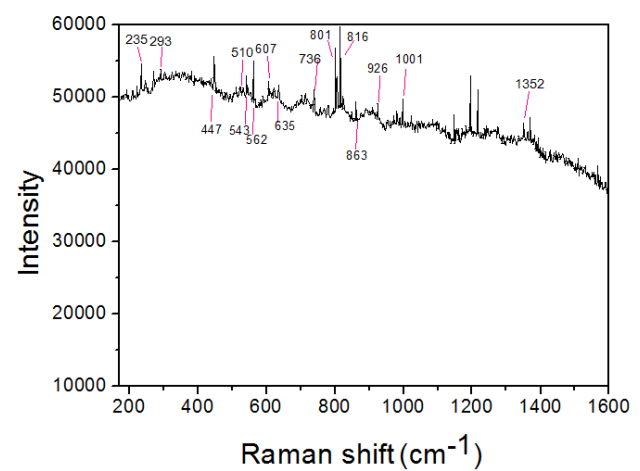

Fig. 9. The Raman spectrum of the film of the iron surface after $7 \mathrm{~h}$ of immersion time in $0.1 \mathrm{M} \mathrm{NaCl}$ containing $50 \mathrm{mg} \mathrm{L}^{-1}$ of Curcuma extract at $25^{\circ} \mathrm{C}$.

In (Figure 9), the band at $562 \mathrm{~cm}^{-1}$ is related to the $\mathrm{Fe}-\mathrm{O}$ bending vibration (Ahangaran, Hassanzadeh, \& Nouri, 2013). The adsorption of organic compounds depends mainly on the presence of a functional group (-OH). It was inferred that phenolic components coordinated with $\mathrm{Fe}^{2+}$ through the phenolic oxygen, ethereal oxygen, and carbonyl oxygen, resulting in the formation of the $\mathrm{Fe}^{2+}$-Inh complexes at the anodic sites of the metal surface. Thus, the FTIR spectral study leads to the conclusion that the protective film consists of the $\mathrm{Fe}^{2+}$ - Inh complexes (Ahangaran, Hassanzadeh, \& Nouri, 2013). 


\section{Conclusions}

Aqueous Curcuma extract is an excellent inhibitor of iron corrosion in near-neutral chloride-containing media, even at very low concentrations. It is a naturally derived and environmentally friendly corrosion inhibitor for iron in $0.1 \mathrm{M} \mathrm{NaCl}$ solution. The following conclusions can be derived from the experimental results discussed above:

- The electrochemical results include the corrosion potential's dainty displacement; the measurements showed that the investigated extracts acted as adsorption inhibitors on the iron surface.

- The action of the extract as a corrosion inhibitor for iron in chloride media can be considered as a chemisorption process because $\Delta \mathrm{G}^{\circ}$ are more negative than $-50 \mathrm{~kJ}$ $\mathrm{mol}^{-1}$.

- With the addition of aqueous Curcuma extract, the inhibition efficiency of iron in $0.1 \mathrm{M} \mathrm{NaCl}$ increases with increasing inhibitor concentration and reaches a value of $74.1 \%$ at room temperature and decreased with temperature to attain a value of $54.7 \%$ at $50{ }^{\circ} \mathrm{C}$.

- The presence of an inhibitor affects the corrosion potential and changes the surface morphology.

- SEM/EDX analysis showed the presence of a layer on the iron surface when corrosion products accumulate due to elevated temperature conditions.

\section{References}

Abdel-Gaber, A. M.; Abd-El-Nabey, B. A.; Sidahmed, I. M.; El-Zayady, A. M. and Saadawy, M. (2006). Inhibitive action of some plant extracts on the corrosion of steel in acidic media. Corrosion Science, 48(9):2765-2779.

Ahangaran, F.; Hassanzadeh, A. and Nouri, S. (2013). Surface modification of
Fe3O4@SiO2 microsphere by silane coupling agent. International Nano Letters, 3(1):3-7.

Ateya, B. G.; El-Anadouli, B. E. and ElNizamy, F. M. (1984). The adsorption of thiourea on mild steel. Corrosion Science, 24(6):509-515.

Banerjee, G. and Malhotra, S. N. (1992). Contribution to adsorption of aromatic amines on mild steel surface from $\mathrm{HCl}$ solutions by impedance, UV, and Raman spectroscopy. Corrosion, 48(1):10-15.

Behpour, M.; Ghoreishi, S. M.; Khayatkashani, M. and Soltani, N. (2012). Green approach to corrosion inhibition of mild steel in two acidic solutions by the extract of Punica granatum peel and main constituents. Materials Chemistry and Physics, 131(3):621-633.

Bernard A. Boukamp. (1986). A package ForImpedance/Admittance Data Analysis. Solid State Ionics, 18\&19:136-140.

Bilgiç, S. and Çaliskan, N. (1999). Effect of N-(1-toluidine) salicylaldimine on the corrosion of austenitic chromium-nickel steel. Applied Surface Science, 152(1):107-114.

Cole, K. S. and Cole, R. H. (1941). Dispersion and absorption in dielectrics I. Alternating current characteristics. The Journal of Chemical Physics, 9(4):341351.

Da Rocha, J. C.; Da Cunha, Ponciano.; Gomes, J. A. and D'Elia, E. (2010). Corrosion inhibition of carbon steel in hydrochloric acid solution by fruit peel aqueous extracts. Corrosion Science, 52(7):2341-2348.

Deng, S. and Li, X. (2012). Inhibition by Ginkgo leaves extract of the corrosion of steel in $\mathrm{HCl}$ and $\mathrm{H}_{2} \mathrm{SO}_{4}$ solutions., 
Corrosion Science, 407-415.

Deus, J. M.; Freire, L.; Montemor, M. F. and Nóvoa, X. R. (2012). The corrosion potential of stainless steel rebars in concrete: Temperature effect. Corrosion Science, 65:556-560.

Donahue, F. M. and Nobe, K. (1965). Theory of Organic Corrosion Inhibitors Adsorption and Linear Free Energy Relationships. Journal of the Electrochemical Society, 112(9):886-891.

Durnie, W.; Marco, R. De.; Jefferson, A.; Kinsella, B.; Soc, J. E. et al. (1999). Development of a Structure-Activity Relationship for Oil Field Corrosion Inhibitors. Journal of The Electrochemical Society, 146(5):1751-1756.

Eduok, U. M.; Umoren, S. A. and Udoh, A. P. (2012). Synergistic inhibition effects between leaves and stem extracts of Sida acuta and iodide ion for mild steel corrosion in $1 \mathrm{M} \mathrm{H}_{2} \mathrm{SO}_{4}$ solutions. Arabian Journal of Chemistry, 5(3):325-337.

E.E. Oguzie. (2008). Evaluation of the inhibitive effect of some plant extracts on the acid corrosion of mild steel. Corros. Sci., 50:2993.

El-Etre, A. Y. and Abdallah, M. (2000). Natural honey as corrosion inhibitor for metals and alloys. II. C-steel in high saline water. Corrosion Science, 42(4):731-738.

El-Hajjaji, F.; Belghiti, M. E.; Hammouti, B.; Jodeh, S.; Hamed, O. et al. (2018). Adsorption and corrosion inhibition effect of 2mercaptobenzimidazole (surfactant) on a carbon steel surface in an acidic medium: Experimental and monte carlo simulations. Portugaliae Electrochimica Acta, 36(3):197-212.

Etteyeb, N. and Nóvoa, X. R. (2016).
Inhibition effect of some trees cultivated in arid regions against the corrosion of steel reinforcement in alkaline chloride solution. Corrosion Science, 112:471-482.

Fattah-alhosseini, A.; Saatchi, A.; Golozar, M. A. and Raeissi, K. (2009). The transpassive dissolution mechanism of 316L stainless steel. Electrochimica Acta, 54(13):3645-3650.

FAUSTIN, M. (2013) Etude de l'effet des alcaloïdes sur la corrosion de l'acier C38 en milieu acide chlorhydrique $1 \mathrm{M}$ : Application à Aspidosperma album et Geissospermum laeve (Apocynacées). Ph.D. thesis, Institut de l'Enseignement Supérieur de la Guyane, Cayenne,Guyane.

Fiori-Bimbi, M. V., Alvarez, P. E., Vaca, H. and Gervasi, C. A. (2015). Corrosion inhibition of mild steel in HCL solution by pectin. Corrosion Science, 92:192-199.

Gomma, G. K. (1998). Influence of copper cation on inhibition of corrosion for steel in presence of benzotriazole in sulfuric acid. Materials Chemistry and Physics, 55(2):131-138.

Guitián, B.; Nóvoa, X. R. and Puga, B. (2011). Electrochemical Impedance Spectroscopy as a tool for materials selection: Water for haemodialysis. Electrochimica Acta, 56(23):7772-7779.

Johnsirani, V.; Rajendran, S.; Nagar, A. A. and Rajan, R. N. (2013). Corrosion inhibition by an aqueous extract of curcumin dye for carbon steel in sea water. Eur. Chem. Bull, 2(6):401-406.

Joiret, S.; Keddam, M.; Nóvoa, X. R.; Pérez, M. C.; Rangel, C. et al. (2002). Use of EIS, ring-disk electrode, EQCM and Raman spectroscopy to study the film of oxides formed on iron in $1 \mathrm{M} \mathrm{NaOH}$. Cement and Concrete Composites, 24(1):715. 
Khamis, E.; Bellucci, F. and Latanision, R. M. (1991). Acid Corrosion Inhibition of Nickel by 2- ( Triphenosphoranylidene ) Succinic Anhydride. Corrosion, 47(9):677686.

Lebrini, M., Robert, F., Lecante, A. and Roos, C. (2011). Corrosion inhibition of C38 steel in 1M hydrochloric acid medium by alkaloids extract from Oxandra asbeckii plant. Corrosion Science, 53(2):687-695.

Lorenz, W. J. and Mansfeld, F. (1981). Determination of corrosion rates by electrochemical DC and AC methods. Corrosion Science, 21(9-10):647-672.

Houyi, Ma.; Cheng, X.; Li, G.; Chen, S.; Quan, Z. et al. (2000). The influence of hydrogen sulfide on corrosion of iron under different conditions. Corrosion Science, 42(10):1669-1683.

Okafor, P. C.; Ikpi, M. E.; Uwah, I. E.; Ebenso, E. E.; Ekpe, U. J. et al. (2008). Inhibitory action of Phyllanthus amarus extracts on the corrosion of mild steel in acidic media. Corrosion Science, 50(8):2310-2317.

Okafor, P. C.; Ebenso, E. E. and Ekpe, U. J. (2010). Azadirachta indica extracts as corrosion inhibitor for mild steel in acid medium. International Journal of Electrochemical Science, 5(7):978-993.

Orazem, M. E., Frateur, I., Tribollet, B., Vivier, V., Marcelin, S., Pébère, N., Bunge, A. L., White, E. A., Riemer, D. P. and Musiani, M. (2013). Dielectric Properties of Materials Showing ConstantPhase-Element (CPE) Impedance Response. Journal of The Electrochemical Society, 160(6):C215-C225.

P. M. S. Monk.; Roger, J. Mortimer.; David, R. R. (2008) Electrochromism: Fundamentals and Applications, WileyVCH, Weinheim, Germany. Pp. 203.
Qafsaoui, W.; Taouil, A. E.; Kendig, M. W.; Cachet, H.; Joiret, S. et al. (2018). Coupling of electrochemical, electrogravimetric, and surface analysis techniques to study dithiocarbamate/bronze interactions in chloride media. Corrosion Science, 130:190-202.

Rahim, A. A.; Rocca, E.; Steinmetz, J.; Kassim, M. J.; Adnan, R. et al. (2007). Mangrove tannins and their flavanoid monomers as alternative steel corrosion inhibitors in acidic medium. Corrosion Science, 49(2):402-417.

Sherif, E. S. M.; Erasmus, R. M. and Comins, J. D. (2010). In situ Raman spectroscopy and electrochemical techniques for studying corrosion and corrosion inhibition of iron in sodium chloride solutions. Electrochimica Acta, 55(11):3657-3663.

Talebian, M.; Raeissi, K.; Atapour, M.; Fernández-Pérez, B. M.; Salarvand, Z. et al. (2018). Inhibitive effect of sodium (E)4-(4-nitrobenzylideneamino)benzoate on the corrosion of some metals in sodium chloride solution. Applied Surface Science, 447:852-865.

Tian, H.; Li, W.; Liu, A.; Gao, X.; Han, P. et al. (2018). Controlled delivery of multi-substituted triazole by metal-organic framework for efficient inhibition of mild steel corrosion in neutral chloride solution. Corrosion Science, 131:1-16.

Torres, V. V.; Amado, R. S.; de Sá, C. F.; Fernandez, T. L.; Riehl, C. A. da S. et al. (2011). Inhibitory action of aqueous coffee ground extracts on the corrosion of carbon steel in $\mathrm{HCl}$ solution. Corrosion Science, 53(7):2385-2392.

\section{Submitted $\quad: 18 / 12 / 2019$}

Revised : 21/07/2020 
Accepted : 22/07/2020

DOI $\quad: 10.48129 /$ kjs.v48i2.8855 